Supporting Information

\title{
Europium luminescence used for logic gate and ions sensing with enoxacin as the antenna
}

Lixia Lu ${ }^{\dagger \dagger}$, Chuanxia Chen ${ }^{\dagger+}$, Dan Zhao ${ }^{\dagger *}$, Jian Sun*,†, and Xiurong Yang*,†

†State Key Laboratory of Electroanalytical Chemistry, Changchun Institute of Applied Chemistry, Chinese Academy of Sciences, Changchun, Jilin 130022, China

University of Chinese Academy of Sciences, Beijing 100049, China

*Fax: +86 431 85689278. E-mail: xryang@,ciac.ac.cn 


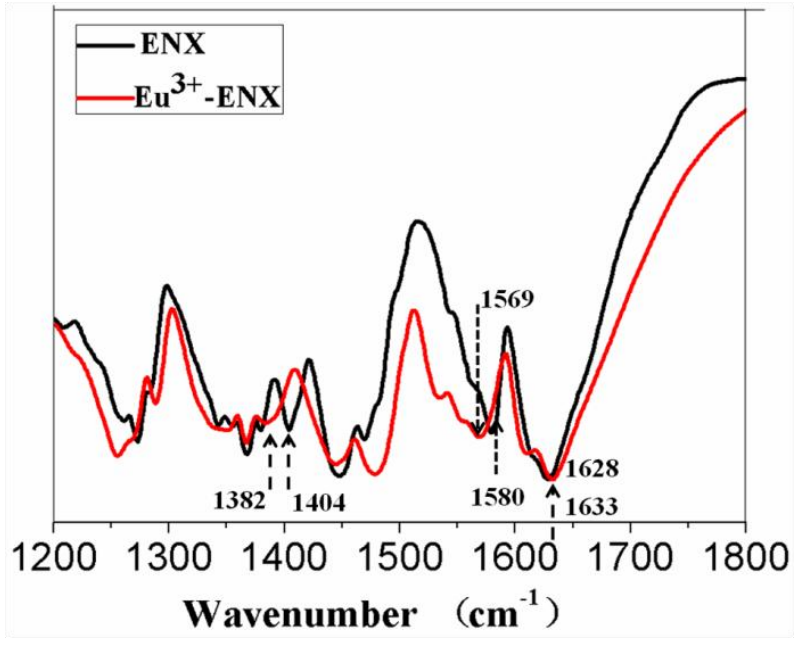

Figure S1. FTIR spectra of ENX and $\mathrm{Eu}^{3+}$-ENX complex.
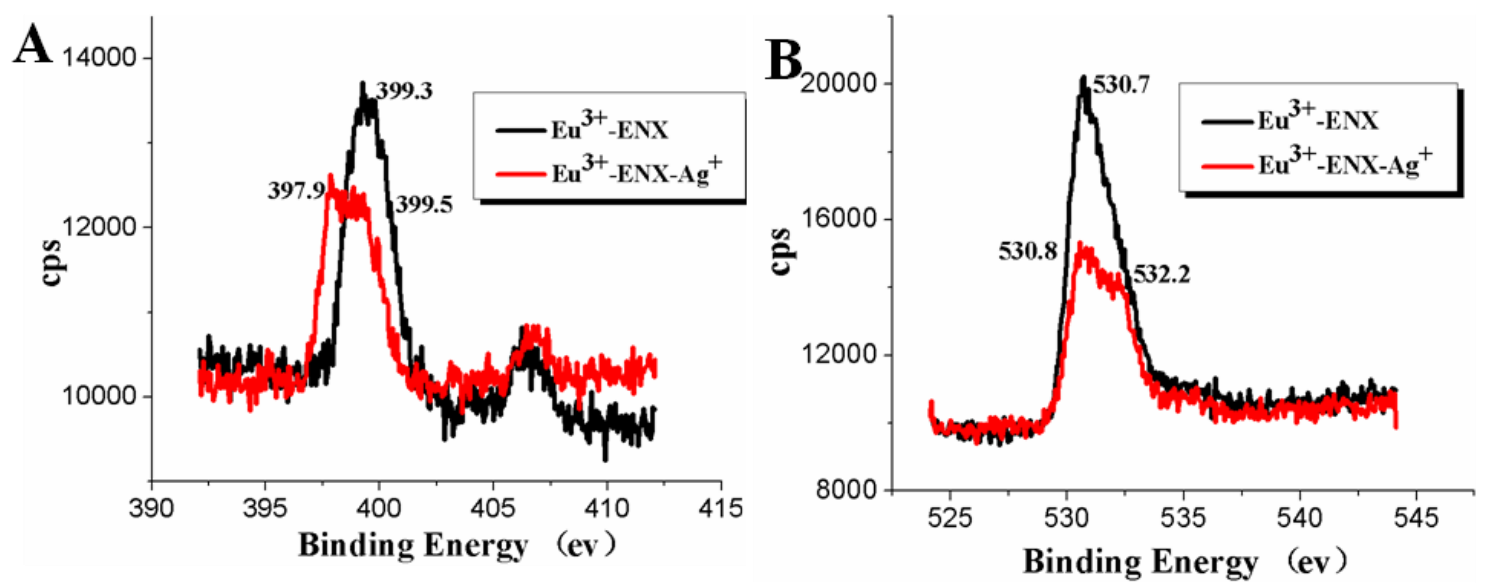

Fugure S2. N 1s (A) and O 1s XPS for $\mathrm{Eu}^{3+}-\mathrm{ENX}$ and $\mathrm{Eu}^{3+}-\mathrm{ENX}-\mathrm{Ag}^{+}$system. 


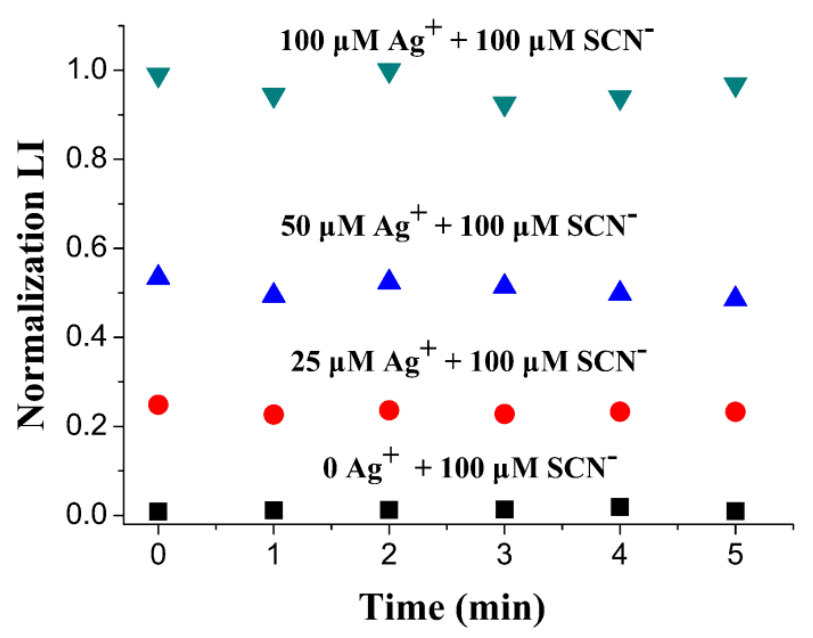

Figure S3. The effects of incubation time after blended on the luminescence responses at $614 \mathrm{~nm}$ of the $\mathrm{Eu}^{3+} / \mathrm{ENX} / \mathrm{Ag}^{+} / \mathrm{SCN}^{-}$system in the presence of different concentrations of $\mathrm{Ag}^{+}$.

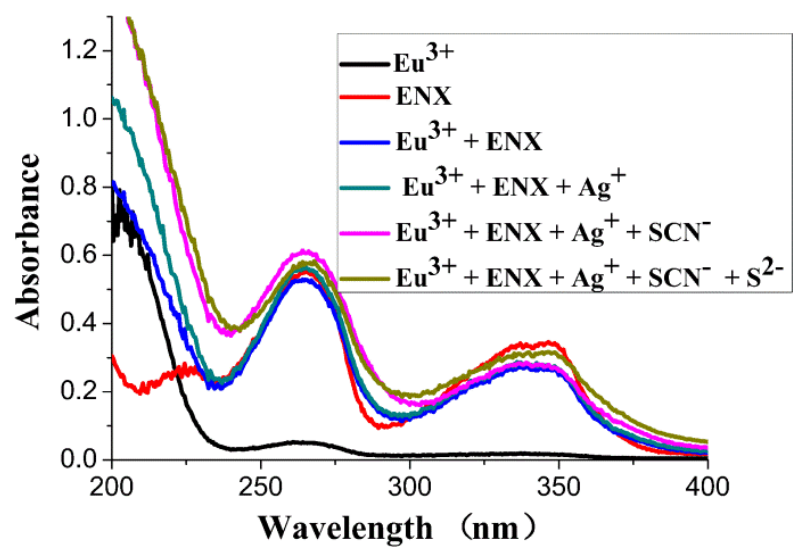

Figure S4. The absorbance spectra of solutions with different contents. 


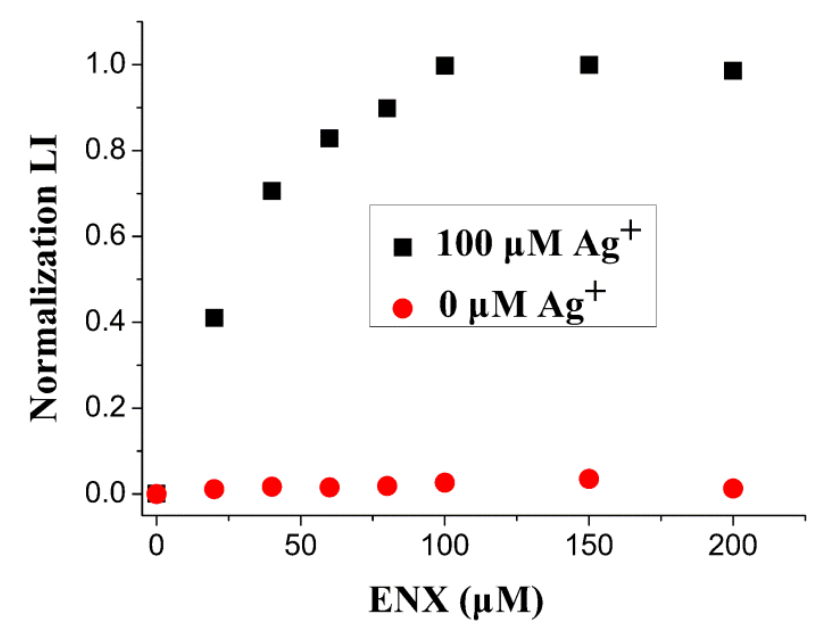

Figure S5. Luminescence responses of $\mathrm{Eu}^{3+} / \mathrm{ENX} / \mathrm{Ag}^{+} / \mathrm{SCN}^{-}$(with $200 \mu \mathrm{M} \mathrm{SCN}^{-}$added) system with $\mathrm{Ag}^{+}$concentrations of 0 and $100 \mu \mathrm{M}$ in the presence of different concentrations of $\operatorname{ENX}(0,20,40,60,80,100,150,200 \mu \mathrm{M})$ in HEPES buffer, pH 7.4.

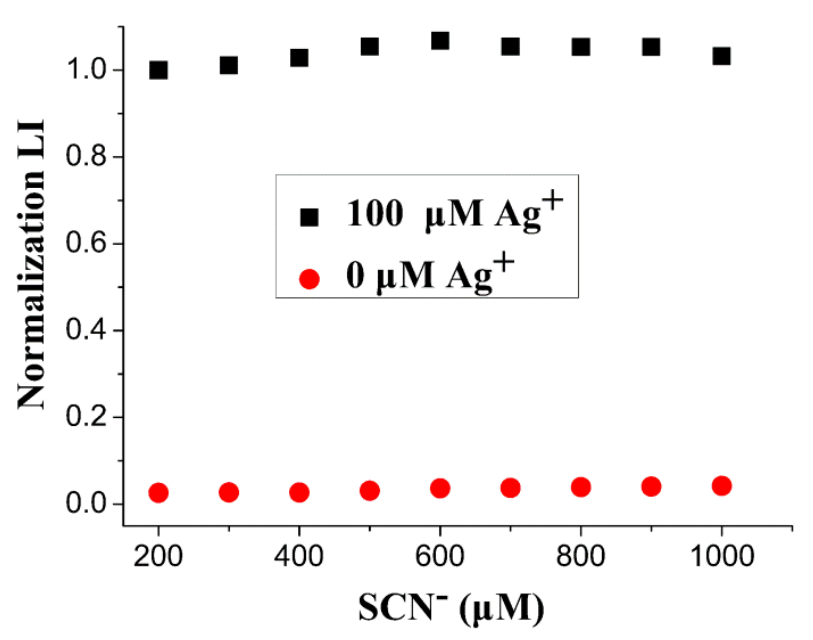

Figure S6. The effects of $\mathrm{SCN}^{-}$concentrations when it exceeds $200 \mu \mathrm{M}$ on the luminescence responses at $614 \mathrm{~nm}$ of the $\mathrm{Eu}^{3+} / \mathrm{ENX} / \mathrm{Ag}^{+} / \mathrm{SCN}^{-}$system in the absence and presence of $100 \mu \mathrm{M} \mathrm{Ag}^{+}$. 


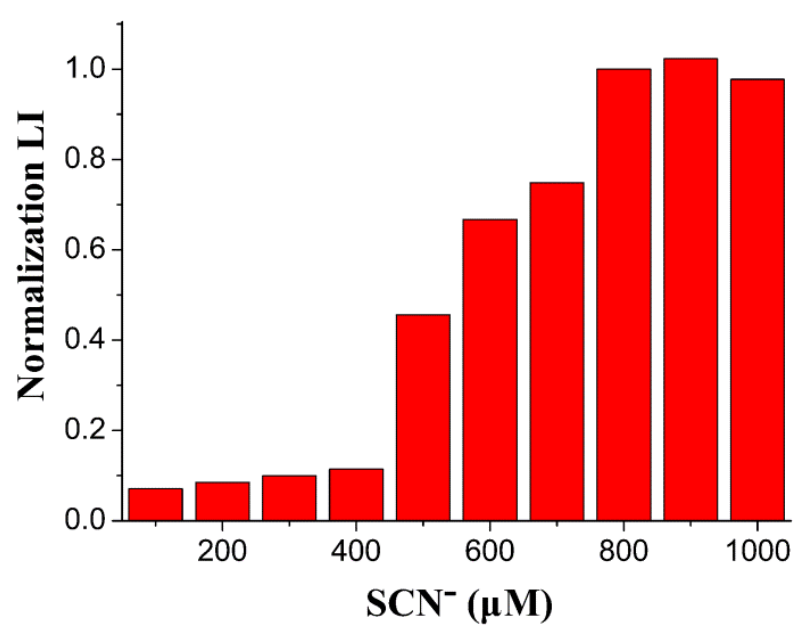

Figure S7. Histograms of the luminescence responses to $100 \mu \mathrm{M} \mathrm{Br}{ }^{-}$of $\mathrm{Eu}^{3+} / \mathrm{ENX} / \mathrm{Ag}^{+} / \mathrm{SCN}^{-}$system in the presence of different concentrations of $\mathrm{SCN}^{-}$.

Table S1. Determination of sulfide level in lake water sample ( $\mathrm{n}=3)$.

\begin{tabular}{cccccc}
\hline $\begin{array}{c}\text { Lake Water } \\
\text { Sample }\end{array}$ & Detected $/ \mu \mathrm{M}$ & Added $/ \mu \mathrm{M}$ & Found $/ \mu \mathrm{M}$ & Recovery $/ \%$ & RSD $/ \%$ \\
\hline & undetected & & & & \\
\hline & 2 & 1.96 & 98 & 1.6 \\
3 & 5 & 5.25 & 105 & 5.3 \\
4 & 10 & 10.11 & 101 & 3.2 \\
5 & 15 & 15.67 & 104 & 2.3 \\
\hline
\end{tabular}

